\title{
ISSR markers to explore entomopathogenic fungi genetic diversity: Implications for biological control of tobacco pests
}

\author{
Maria Florencia Vianna ${ }^{l}$, Sebastian Pelizza ${ }^{l}$, María Leticia Russo ${ }^{1} * \odot$, \\ Andrea Toledo $^{2}$, Cecilia Mourelos ${ }^{2}$ and Ana Clara Scorsetti ${ }^{1}$ \\ ${ }^{1}$ Instituto Spegazzini, Universidad Nacional de La Plata, La Plata, Buenos Aires, Argentina \\ ${ }^{2}$ Centro de Investigaciones en Fitopatologia, Universidad Nacional de La Plata, \\ La Plata, Buenos Aires, Argentina \\ *Corresponding author (Email, leticiarusso@conicet.gov.ar)
}

MS received 15 March 2020; accepted 6 October 2020

\begin{abstract}
Tobacco is one of the major industrial crops cultivated worldwide. Chemical control is the main method employed to reduce damage by insect pests. The use of entomopathogenic fungi represents an alternative to replace insecticides. The search for effective strains in the field constitutes a first step when developing a formulation. The objective of this work was to study genetic differences among isolates of entomopathogenic fungi obtained from tobacco grown soils using ISSR markers. The pathogenicity of the strains towards Helicoverpa gelotopoeon and Diabrotica speciosa was also assessed in order to search for a relationship between virulence and genetic diversity. Nineteen isolates were identified according to morphological features and molecular techniques as Beauveria bassiana (11) and Purpureocillium lilacinum (8). The diversity tree generated by ISSR analysis showed a high diversity among the strains. The pathogenicity towards $H$. gelotopoeon and D. speciosa was assessed and the logistic models generated showed that B. bassiana isolates LPSc1215 and LPSc1364 were the most pathogenic against both insect pests tested. In the diversity tree, these strains were grouped in a same cluster with a similarity level of approximately $85 \%$, indicating a possible relationship between virulence and the band pattern generated.
\end{abstract}

Keywords. Beauveria bassiana; Diabrotica speciose; genetic polymorphism; Helicoverpa gelotopoeon; pathogenicity; Purpureocillium lilacinum

\section{Introduction}

Tobacco (Nicotiana tabacum L.) is one of the major industrial crops, with a cultivated area of approximately 3.9 million hectares worldwide. Many insect pests attack this crop at different stages of its life cycle, affecting the development of the plant and therefore decreasing crop yield. The most harmful insect affecting this crop are those belonging to Lepidoptera and Coleoptera (Mercado Cardenas et al. 2013; Yang et al. 2019). The main method to reduce damage is the use of chemical insecticides that seriously affect the environment and human health, especially of farmers that are in direct contact with them (Da Silva et al. 2014).

Biological control has arisen to amend adverse effects of conventional plant protection strategies, particularly fungal entomopathogens are promising organisms among these ecofriendly practices. Species within the genera Beauveria, Lecanicillium, Metarhizium and Purpureocillium have been commercially formulated with more than 200 products available in the market (de Barros et al. 2015; de Faria and Wraight 2007; Mishra et al. 2015; Pathan et al. 2019; Sandhu et al. 2017).

Accurate taxonomic determination and knowledge about genetic diversity of strains constitutes the first step when searching for a suitable biocontrol agent (Fernández Bravo 2017; Zimmermann 2007). In this sense, a promising application of fingerprints techniques is that they may allow tracing organisms in the field when these are utilized as formulations with biological control purposes and therefore the way strains perform and persist 
on the field (Takatsuka 2007). Tigano-Milani et al. (1995) proposed the hypothesis that more than one haplotype may be required to initiate and maintain a fungal epizootic in an insect population. According to this, the genetic diversity of the strains would be the factor that would allow the fungi to adapt to changing environmental conditions and to successfully attack different insect populations (Cruz et al. 2006). In line with this, PCR molecular markers such as Amplified Fragment Length Polymorphism (RFLP), Random Amplified Polymorphic DNA (RAPD) and Inter Simple Sequence Repeats (ISSR) have been used as effective tools to detect genetic variability among fungal populations (Enkerli and Widmer 2010; Fernandes et al. 2006; Serna-Domínguez et al. 2019; Sevim et al. 2012; Trissi et al. 2013). DNA fingerprinting with ISSR markers is considered to provide superior discrimination among fungal isolates compared to other methods because it produces quite variable fingerprints with a large number of fragments throughout the genome (Taylor et al. 1999). Concerning fungal entomopathogens, ISSR markers have been successfully used to detect genetic variability within several species of Hypocreales like Beauveria bassiana (Bals.-Criv.) Vuill. (Estrada et al. 2007; Rehner and Buckley 2005; Takatsuka 2007; Toledo et al. 2019), Metarhizium anisopliae (Metsch.) Sorokin (Enkerli et al. 2005; Oulevey et al. 2009) and Paecilomyces fumosoroseus (= Isaria fumosorosea) Wize (Dalleau-Clouet et al. 2005), constituting a first step in the selection of pathogenic strains according to their genotype.

The objective of this investigation was to study genetic differences among entomopathogenic fungi associated to tobacco crop using ISSR markers and to determine their entomocidal capacity against to major tobacco pests, Helicoverpa gelotopoeon Dyar (Lepidoptera: Noctuidae) and Diabrotica speciosa Germar (Coleoptera: Chrysomelidae) under laboratory conditions in order to establish a connection between fungal genetic profiles and their capacity to kill insects.

\section{Material and methods}

\subsection{Fungal isolation and morphological characterization}

Fungal isolates were obtained from soil samples from seven tobacco (N. tabacum L.) crops. Samples were collected during summer in Perico, Jujuy province $\left(24^{\circ} 23^{\prime} \mathrm{S}-65^{\circ} 08^{\prime} \mathrm{W}\right)$. Five compound soil samples from each crop (from a depth up to $12 \mathrm{~cm}$ ) were collected with a sterile shovel, placed into polyethylene plastic bags and stored at $4{ }^{\circ} \mathrm{C}$ in the laboratory for no longer than a month until they were examined for the presence of entomopathogenic fungi.

To accomplish entomopathogenic fungi isolation from soil, serial dilution protocol was performed according to Lecuona (1996). For each sample, six dilutions with five repetitions each were obtained and $100 \mu \mathrm{l}$ were spread with a Drigalsky spreader in Petri dishes containing selective medium for entomopathogenic fungi (Posadas et al. 2012). A total of 1,050 plates were analyzed for the presence of entomopathogenic fungi. These were stored at $24^{\circ} \mathrm{C}$ in the darkness for a period of 10 to 15 days. Entomopathogenic fungal colonies were detected under binocular microscope and transferred to potato dextrose agar (PDA) (Britania ${ }^{\circledR}$ S.A., Buenos Aires, Argentina) plates. Microscopical mounts were made to confirm fungal morphological identity according to taxonomic keys and monographs of Nagamani et al. (2006); Domsch et al. (2003); Samson et al. (1988); Seifert et al. (2011). For each isolate, monosporic colonies were obtained and preserved at the Micological Collection of the Botanical Institute Carlos Spegazzini, Argentina (LPSc), under their respective accession numbers.

\subsection{Diversity analysis}

DNA was extracted from eleven strains of B. bassiana and eight strains of Purpureocillium lilacinum (Thom) Luangsa-ard, Houbraken, Hywel-Jones \& Samson grown on liquid Sabouraud dextrose plus 1\% yeast extract (SDY 1\%) medium after 7 day's incubation, without agitation, at $25^{\circ} \mathrm{C}$ in the darkness. Extraction was performed according the methodology proposed by Aljanabi and Martinez (1997). DNA quality was assessed by electrophoresis on $0.7 \% \mathrm{w} / \mathrm{v}$ agarose gels supplemented with ethidium bromide $\left(100 \mathrm{ng} \mathrm{ml}^{-1}\right.$ ) and its quantity was estimated by comparison with a molecular marker control of known concentration (Lambda Phage Genome digested with Hind III Promega Biotech) using the image analyzer (SYNGENE GeneTools).

Diversity analysis was performed using the ISSR primers 826 (5'-ACCACACACACACACC- $\left.3^{\prime}\right)$, BA3 (5'-ACACACACACACACACCT-3') and KA5 (5'CTACACACACACACACAC- $3^{\prime}$ ) selected considering previous results obtained by Toledo et al. (2019). The ISSR-PCR reactions were performed on a MJ Research (PTC-150 MiniCycler) and each amplification reaction 
had a total volume of $15 \mu$ containing $1 \times$ buffer $(500$ $\mathrm{mM} \mathrm{KCl} ; 100 \mathrm{mM}$ Tris- $\mathrm{HCl}, \mathrm{pH} 9.0$ at $25^{\circ} \mathrm{C} ; 1 \%$ Triton X-100), $2 \mathrm{mM}$ (primers 826 and KA5) or 2.5 $\mathrm{mM}$ (primer BA3) of $\mathrm{MgCl}_{2}, 0.25 \mathrm{mM}$ each dNTP, 50 ng of each primer, $1 \mathrm{U}$ Taq DNA polymerase and approximately $50 \mathrm{ng}$ of template DNA (reagents Inbio Highway ${ }^{\circledR}$, Tandil, Buenos Aires, Argentina). PCR program was as follows: initial denaturation at $94^{\circ} \mathrm{C}$ for 5 min, followed by 30 cycles of denaturation at $94^{\circ} \mathrm{C}$ for $45 \mathrm{~s}$, annealing at $48^{\circ} \mathrm{C}$ for $45 \mathrm{~s}$ and extension at $72^{\circ} \mathrm{C}$ for $3 \mathrm{~min}$, with an additional final extension step at $72^{\circ} \mathrm{C}$ for $5 \mathrm{~min}$. PCR products were resolved by electrophoresis on $1.5 \% \mathrm{w} / \mathrm{v}$ agarose gels supplemented with ethidium bromide $\left(100 \mathrm{ng} \mathrm{ml}^{-1}\right)$ using as control an internal standard the DNA marker 100-1000 bp (Inbio Highway ${ }^{\circledR}$, Tandil, Buenos Aires, Argentina). The ISSR banding patterns generated were analyzed with the software Past 3 and a dendrogram was built using the similarity matrix of DICE and the Unweighted Pair Group Method with Arithmetic Mean (UPGMA).

\subsection{Molecular identification}

For further isolates identification, their molecular identity was confirmed by choosing eight isolates to amplify and sequence the ribosomal internal transcribed spacers (ITS) and the translation elongation factor 1-alpha (TEF1- $\alpha$ ) genes. The isolates were selected according to their location in the previously built diversity analysis dendrogram.

DNA extraction was performed as describe above for the diversity analysis. The universal primers ITS5 $\left(5^{\prime}-\right.$ GGAAGTAAAAGTCGTAACAAGG- $3^{\prime}$ ) and ITS4 (5'-TCCTCCGCTTATTGATATGC-3') (White et al. $1990)$ and primers 983F (5'-GCYCCYGGHCAYCGTGAYTTYAT-3') and 2218R (5'- ATGACACCRACRGCRACRGTYTG- $3^{\prime}$ ) (Rehner and Buckley 2005) were used to amplify ITS and TEF $1-\alpha$ regions, respectively. The reaction mix contained Buffer $1 \times(500 \mathrm{mM} \mathrm{KCl} ; 100 \mathrm{mM}$ Tris- $\mathrm{HCl}$, pH 9.0 at $25^{\circ} \mathrm{C} ; 1 \%$ Triton $\left.\mathrm{X}-100\right), 1.5 \mathrm{mM}$ of $\mathrm{MgCl}_{2}, 0.2 \mathrm{mM}$ of each dNTP, $50 \mathrm{ng}$ of each primer, $1 \mathrm{U}$ of Taq DNA polymerase and approximately $20 \mathrm{ng}$ of DNA (Inbio Highway ${ }^{\circledR}$, Tandil, Buenos Aires, Argentina reagents). The PCR reactions were performed in a MJ Research (PTC-150 MiniCycler) termocycler, and the program consisted in an initial DNA denaturation at $94^{\circ} \mathrm{C}$ for 4 min followed by 33 cycles of denaturation at $94^{\circ} \mathrm{C}$ for $1 \mathrm{~min}, 45 \mathrm{~s}$ at $56^{\circ} \mathrm{C}$ for ITS and $1 \mathrm{~min}$ at $48^{\circ} \mathrm{C}$ for $\mathrm{TEF} 1-\alpha, 1 \mathrm{~min}$ at $72^{\circ} \mathrm{C}$ and finally an elongation step at $72^{\circ} \mathrm{C}$ for $5 \mathrm{~min}$. The amplified PCR products were precipitated in an isopropanol volume and a 0.1 volume of ammonium acetate $3 \mathrm{M}$, this mixture was incubated at $-18^{\circ} \mathrm{C}$ for $12 \mathrm{~h}$ and later was centrifuged at $15,000 \mathrm{~g}$ for $15 \mathrm{~min}$. The DNA pellet was washed with ethanol $70 \%$, dried and dissolved in distilled sterile water. The sequencing was performed at the CERELAInstitute (CONICET, Tucumán, Argentina). The sequences obtained were submitted to the National Center for Biotechnology Information (NCBI) GenBank database (www.ncbi.nlm.nih.gov) for gene annotation. Sequences were edited using BioEdit software version 7.0.5 (Hall 1999), and posteriorly used to perform a phylogenetic analysis that included the sequences of the isolates of Beauveria and Purpureocillium from this work with sequences of some species for the genera available at the GenBank database including type material of $B$. bassiana ITS= NR_111594.1, TEF1- $\alpha=$ HQ880974.1 and P. lilacinum ITS $=$ NR_111432.1, TEF1- $\alpha=$ EF468792.1. All sequences were aligned with the ClustalW tool of the program Mega5 (Tamura et al. 2011) and the phylogenetic study was carried out using the analysis of maximum likelihood. The statistical support for the nodes was evaluated through 1000 bootstrap replicates.

\subsection{Pathogenicity tests}

Pathogenicity bioassays were performed against third instar larvae of $H$. gelotopoeon and adults of $D$. speciosa. Helicoverpa gelotopoeon eggs were provided by AgIdea Pergamino, Buenos Aires, Argentina (https:// www.agidea.com.ar/) and larvae were fed with artificial diet according to Patana (1977). Diabrotica speciosa adults were collected from the field and were kept in laboratory for a period of fifteen days to prevent any disease from the field (Pilz et al. 2007).

All entomopathogenic strains were tested for their pathogenicity. Each fungal colony was grown on PDA at $25^{\circ} \mathrm{C}$ in the darkness during 14 days. After two weeks, 10 $\mathrm{ml}$ of Tween 80 (Merck®) $0.01 \% \mathrm{v} / \mathrm{v}$ were added to Petri plates to obtain conidia by scraping strains surfaces with a sterile scalpel. The resulting conidial suspensions were filtered with a sterile cloth and subsequently were vortexed for five minutes. Conidial concentration of each suspension was adjusted to $1 \times 10^{8}$ conidia/ml using a Neubauer chamber. Conidial viability was assed according to Ayala Zermeño et al. (2015).

To test strains pathogenicity the immersion method was carried out according to Nussenbaum and Lecuona (2012). Three replicates of 10 individuals for each 
treatment were performed. Insects were submerged individually for fifteen seconds in conidial suspensions, subsequently were lean on sterile filter paper to dry off excess moisture, and finally placed on plastic Petri dishes. Controls were treated only with Tween 80 . Insects were kept on a breeding chamber under uniform and controlled conditions $\left(25 \pm 2{ }^{\circ} \mathrm{C}, 75 \% \mathrm{RH}\right.$, photoperiod 14:10 L: D). Food was provided on daily bases, for $H$. gelotopoeon caterpillars artificial diet according to Patana (1977) was used and for D. speciosa adults, zucchini (Cucurbita pepo) pieces of approximately $0.5 \mathrm{~cm}^{3}$ were offered (Pecchioni 1989).

The number of dead insects on each treatment was recorded for a period of fourteen days. Mortality due to mycosis was asserted by placing cadavers on humid chambers and stored at $25^{\circ} \mathrm{C}$ in the darkness to promote mycelia outgrowth (Powell et al. 2007).

Mortality registered for each strain was adjusted to a logistic model to estimate their pathogenicity as a function of time using StatSoft Statistica software (version 7.1) (2005).

\section{Results}

\subsection{Fungal isolates}

A total of nineteen entomopathogenic fungal isolates were obtained from tobacco grown soil samples using selective media for this type of fungi. According to morphological features, eleven of them were assigned to B. bassiana (Accession numbers: LPSc1210, LPSc1211, LPSc1212, LPSc1213, LPSc1214, LPSc1215, LPSc1216, LPS c1217, LPSc1363, LPSc1364, LPSc1364, and LPSc 1265 ) and eight to $P$. lilacinum (Accession numbers: LPsC1367, LPSc1368, LPSc1369, LPSc1370, LPSc1 371, LPSc1372, LPSc1373, and LPSc1374).

\subsection{Diversity analysis}

The diversity study employing three ISSR primers generated a total of 55 fragments with sizes that ranged between 300 and $1200 \mathrm{pb}$. The primer 826 generated a pattern of 18 bands, the primer BA3 a pattern of 13 bands and the primer KA5 a pattern of 24 bands (figure 1). The topology of the UPGMA-tree showed a high diversity among the strains. The three primers used confirmed the presence of four clusters inside $B$. bassiana group, showing the existence of at least four different haplotypes. Isolate LPSc1363 appeared in the first clade. Isolates LPSc1214,
LPSc1213, LPSc1211, LPSc1212 and LPSc1365 were associated in the second clade, in which the first three isolates were grouped in a subclade and the other two isolates in another subclade. Isolates LPSc1215 and LPSc1364 formed the third clade, while isolates LPSc1217, LPSc1216 and LPSc1210 were grouped in the fourth clade. Similar relationship was observed inside the $P$. lilacinum group, where four different haplotypes were also recorded. The first clade was formed by isolates LPSc1368, LPSc1369, LPSc1370 and LPSc1367, with the two first isolates grouped in a subclade. The second clade was formed by isolates LPSc1372 and LPSc1373, while the third and the fourth clades were formed by isolates LPSc1374 and LPSc1371, respectively (figure 1).

\subsection{Molecular identification}

ITS amplicons from the eight selected strains ( $B$. bassiana LPSc1213, LPSc1216, LPSc1363 and LPSc1364 and P. lilacinum LPSc1370, LPSc1371, LPSc1373 and LPSc1374) considered as representative for each cluster in the ISSR dendrogram had a length of 522 to $576 \mathrm{bp}$ for B. bassiana and of 474 to $486 \mathrm{bp}$ for $P$. lilacinum. TEF1- $\alpha$ amplicons of the same selected isolates had a size of 954 to $956 \mathrm{bp}$ for $B$. bassiana and of 917 to $920 \mathrm{bp}$ for $P$. lilacinum. In the maximum likelihood tree resulting from the phylogenetic analysis of the ITS region, the four isolates of $B$. bassiana were clustered together with the material type of $B$. bassiana NR_111594 in a monophyletic group supported by a bootstrap value of $99 \%$. While Beauveria amorpha, B. caledonica, B. malawiensis and Cordyceps brongniartii, all morphologically-related species, formed an independent clade supported by a bootstrap value of $95 \%$ (figure $2 \mathrm{~A}$ ). In the same tree the $P$. lilacinum isolates selected were clustered in a monophyletic group supported by a bootstrap value of $99 \%$, which included only P. lilacinum representatives, including the sequences of the type material NR_111432.1 (figure 2A). On the other hand, the maximum likelihood tree resulting from the phylogenetic analysis of the TEF1- $\alpha$ showed a similar topology to that observed for ITS regions. All isolates of $B$. bassiana selected in this work were clustered together with $B$. bassiana type material HQ880974.1 in a same clade supported by a bootstrap value of $82 \%$. Likewise, the four isolates of $P$. lilacinum were grouped together with the type material EF468792.1 in a clade integrated only by this species and supported by a bootstrap value of $100 \%$ (figure $2 \mathrm{~B}$ ). 

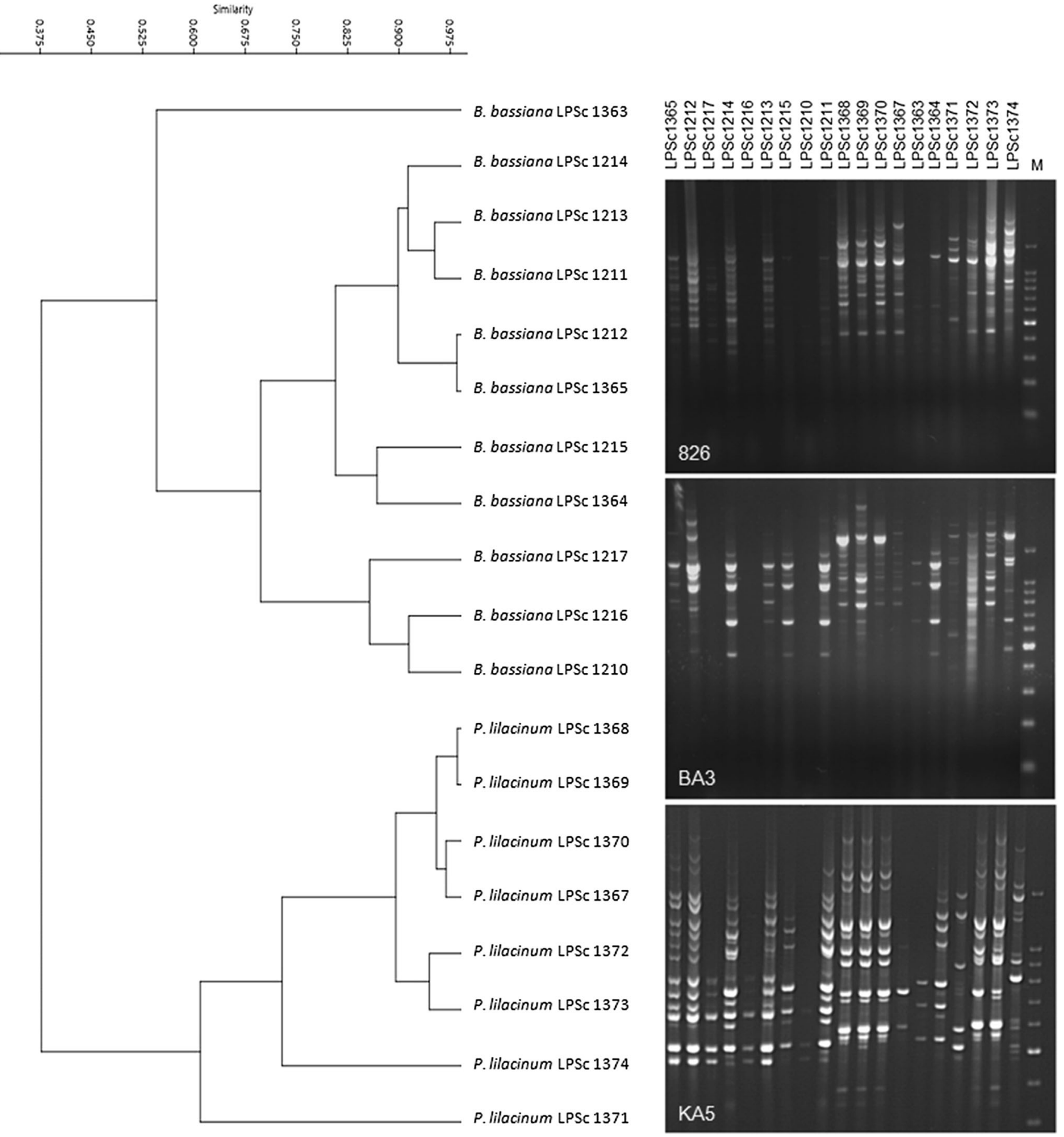

Figure 1. Dendrogram built using the similarity matrix of DICE and the UPGMA including the patterns of bands of Beauveria bassiana and Purpureocillium lilacinum isolates generated by ISSR primers 826 , BA3 and KA5. M = DNA marker 100-1000 bp.

\subsection{Pathogenicity tests}

All isolates tested against $H$. gelotopoeon were adjusted to a logistic model for their pathogenicity as a function of time. Beta values were considered as 0 , and $\mathrm{p}$ values for all models showed values $<0.005$ (table 1 and figure 3). Those isolates that were not pathogenic to larvae were not adjusted to any model.

The strains LPSc1212, LPSc1214, LPSc1215, LPSc1364 and LPSc1365 belonging to B. bassiana exhibited pathogenicity levels above $50 \%$. The isolate LPSc1215 was the most pathogenic to the insect with 

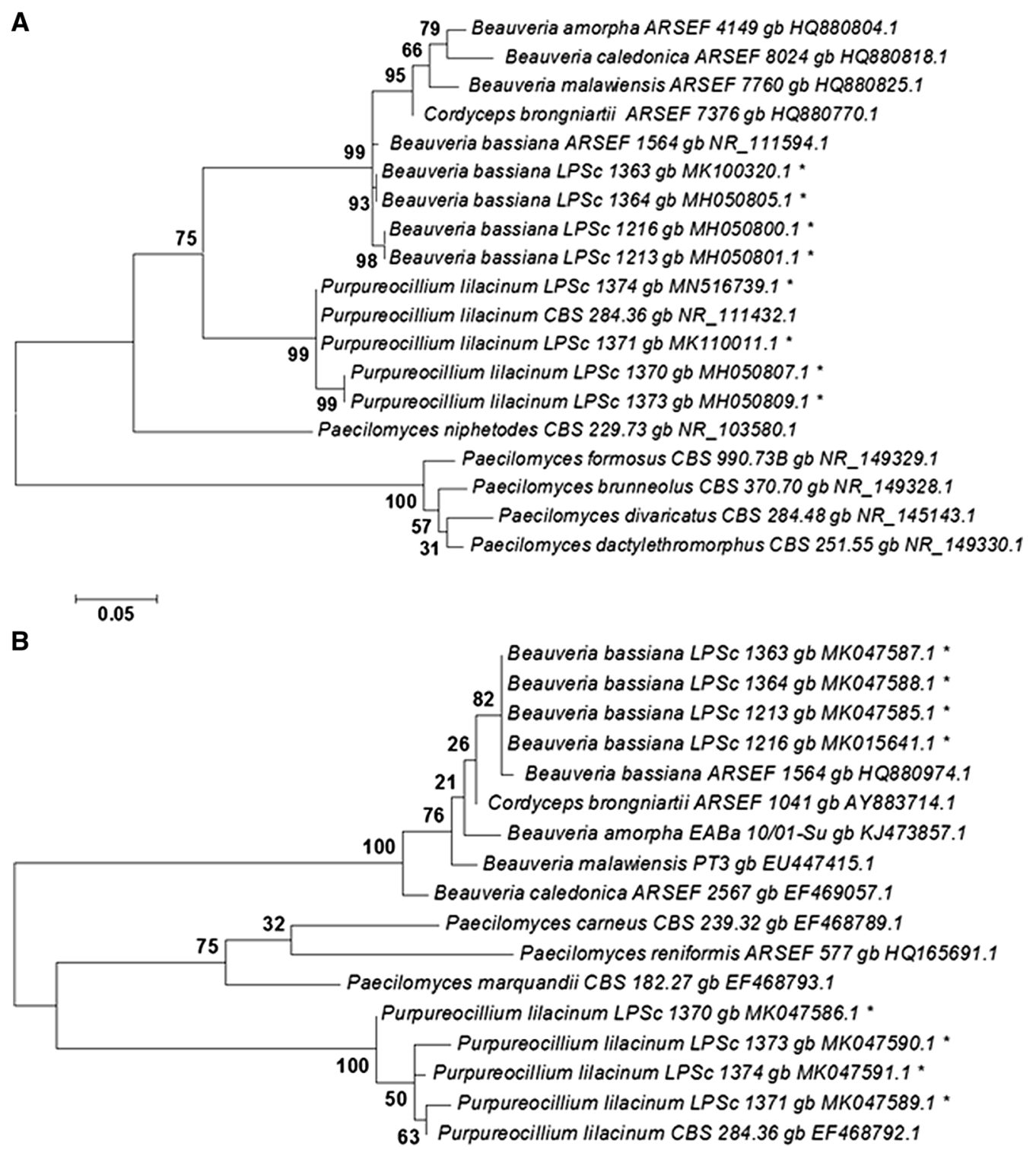

0.02

Figure 2. Phylogenetic tree obtained by the analysis of (A) ITS and (B) TEF1- $\alpha$ sequences from four Beauveria basssiana isolates and four Purpureocillium lilacinum and related groups. Isolates belonging to this work are identified by an * symbol. GeneBank accession numbers of the isolates are provided next to each strain. The bar at the bottom indicates the number of substitutions per site.

$100 \%$ infectivity at 7 days after treatment. Also, isolates LPSc1212 and LPSc1364 showed high levels of pathogenicity with $97 \%$ and $94 \%$ at 11 and 10 days post treatment, respectively. With respect to $P$. lilacinum isolates, only LPSc1371 was pathogenic against H. gelotopoeon larvae, showing a low pathogenicity of $33 \%$ after 7 days post treatment. In addition, a logistic model was chosen as well to analyze the behavior (pathogenicity as a function of time) of isolates towards D. speciosa. Beta values were considered as 0 , and $p$ values for all models showed values
$<0.005$. Alfa and Gama values for the models generated for each strain are presented in table 1 and figure 4. If strains were not pathogenic, no model was adjusted. Only four isolates displayed pathogenicity levels over $50 \%$ against $D$. speciosa. The isolate $B$. bassiana LPSc 1215 was the most pathogenic to the insects reaching $98 \%$ mortality at 11 days while isolate $B$. bassiana LPSc1364 reached $86 \%$ mortality at 12 days. Likewise, $P$. lilacinum isolates LPSc1368 and LPSc1369 showed $81 \%$ and $78 \%$ mortality at 10 and 9 days, respectively. 
Table 1. Pathogenicity of Beauveria bassiana and Purpureocillium lilacinum towards Helicoverpa gelotopoeon and Diabrotica speciose

\begin{tabular}{|c|c|c|c|c|c|c|c|}
\hline \multirow[b]{2}{*}{ Species } & \multirow[b]{2}{*}{ Strain } & \multicolumn{3}{|c|}{ Helicoverpa gelotopoeon } & \multicolumn{3}{|c|}{ Diabrotica speciosa } \\
\hline & & $\begin{array}{l}\text { Maximum } \\
\text { pathogenicity } \\
\text { reached }\end{array}$ & $\begin{array}{l}\text { Pathogenicity } \\
\text { rate }\end{array}$ & $\begin{array}{l}\text { Maximum } \\
\text { pathogenicity } \\
\text { time }\end{array}$ & $\begin{array}{l}\text { Maximum } \\
\text { pathogenicity } \\
\text { reached }\end{array}$ & $\begin{array}{l}\text { Pathogenicity } \\
\text { rate }\end{array}$ & $\begin{array}{l}\text { Maximum } \\
\text { pathogenicity } \\
\text { time }\end{array}$ \\
\hline B. bassiana & $\begin{array}{c}\text { LPSc } \\
1365\end{array}$ & 0.64 & 1.09 & 10 & 0.16 & 1.6 & 8 \\
\hline B. bassiana & $\begin{array}{c}\text { LPSc } \\
1212\end{array}$ & 0.97 & 0.6 & 11 & 0.2 & 1.46 & 10 \\
\hline B. bassiana & $\begin{array}{c}\text { LPSc } \\
1217\end{array}$ & 0.2 & 1.48 & 7 & 0 & 0 & 0 \\
\hline B. bassiana & $\begin{array}{c}\text { LPSc } \\
1214\end{array}$ & 0.54 & 1.05 & 10 & 0.07 & 1.52 & 8 \\
\hline B. bassiana & $\begin{array}{c}\text { LPSc } \\
1216\end{array}$ & 0 & 0 & 0 & 0 & 0 & 0 \\
\hline B. bassiana & $\begin{array}{c}\text { LPSc } \\
1213\end{array}$ & 0.37 & 1.15 & 12 & 0.48 & 1.02 & 10 \\
\hline B. bassiana & $\begin{array}{c}\text { LPSc } \\
1215\end{array}$ & 1.02 & 1.08 & 6 & 0.98 & 1.43 & 11 \\
\hline B. bassiana & $\begin{array}{c}\text { LPSc } \\
1210\end{array}$ & 0.13 & 1.46 & 9 & 0.1 & 1.52 & 11 \\
\hline B. bassiana & $\begin{array}{r}\text { LPSc } \\
1211\end{array}$ & 0.31 & 1.31 & 10 & 0.34 & 1.28 & 9 \\
\hline B. bassiana & $\begin{array}{c}\text { LPSc } \\
1363\end{array}$ & 0.24 & 1.64 & 5 & 0 & 0 & 0 \\
\hline B. bassiana & $\begin{array}{c}\text { LPSc } \\
1364\end{array}$ & 0.94 & 1.32 & 10 & 0.86 & 1.29 & 12 \\
\hline P. lilacinum & $\begin{array}{c}\text { LPSc } \\
1368\end{array}$ & 0 & 0 & 0 & 0.81 & 0.96 & 10 \\
\hline P. lilacinum & $\begin{array}{c}\text { LPSc } \\
1369\end{array}$ & 0 & 0 & 0 & 0.78 & 1.34 & 9 \\
\hline P. lilacinum & $\begin{array}{l}\text { LPSc } \\
1370\end{array}$ & 0 & 0 & 0 & 0.17 & 1.3 & 7 \\
\hline P. lilacinum & $\begin{array}{c}\text { LPSc } \\
1367\end{array}$ & 0 & 0 & 0 & 0.24 & 1.44 & 9 \\
\hline P. lilacinum & $\begin{array}{l}\text { LPSc } \\
1371\end{array}$ & 0.33 & 1.07 & 7 & 0 & 0 & 0 \\
\hline P. lilacinum & $\begin{array}{c}\text { LPSc } \\
1372\end{array}$ & 0 & 0 & 0 & 0.07 & 1.38 & 8 \\
\hline P. lilacinum & $\begin{array}{c}\text { LPSc } \\
1373\end{array}$ & 0 & 0 & 0 & 0 & 0 & 0 \\
\hline P. lilacinum & $\begin{array}{c}\text { LPSc } \\
1374\end{array}$ & 0 & 0 & 0 & 0.13 & $1.11^{*}$ & 11 \\
\hline
\end{tabular}

\section{Discussion}

In the present study, soil samples associated to $N$. tabacum crops were analyzed for the presence of entomopathogenic fungi. A total of 19 isolates were identified according to morphological features and molecular techniques as B. bassiana (11) and P. lilacinum (8). Both species are frequently isolated from natural and agricultural soils (Vega 2008) where their survival is influenced by various factors such as UV radiation, air mobility, water content, temperature (Flint et al. 2002; Thompson et al. 2006; Yang et al. 2019), fertilizers and other chemical inputs (Bruck 2009, Shapiro-Ilan et al. 2013), processing methods (Boetel et al. 2012; Hummel et al. 2015) and soil and crop types (Shapiro-Ilan et al. 2012). The results of our investigations revealed the presence of two of the most effective biological control species among 


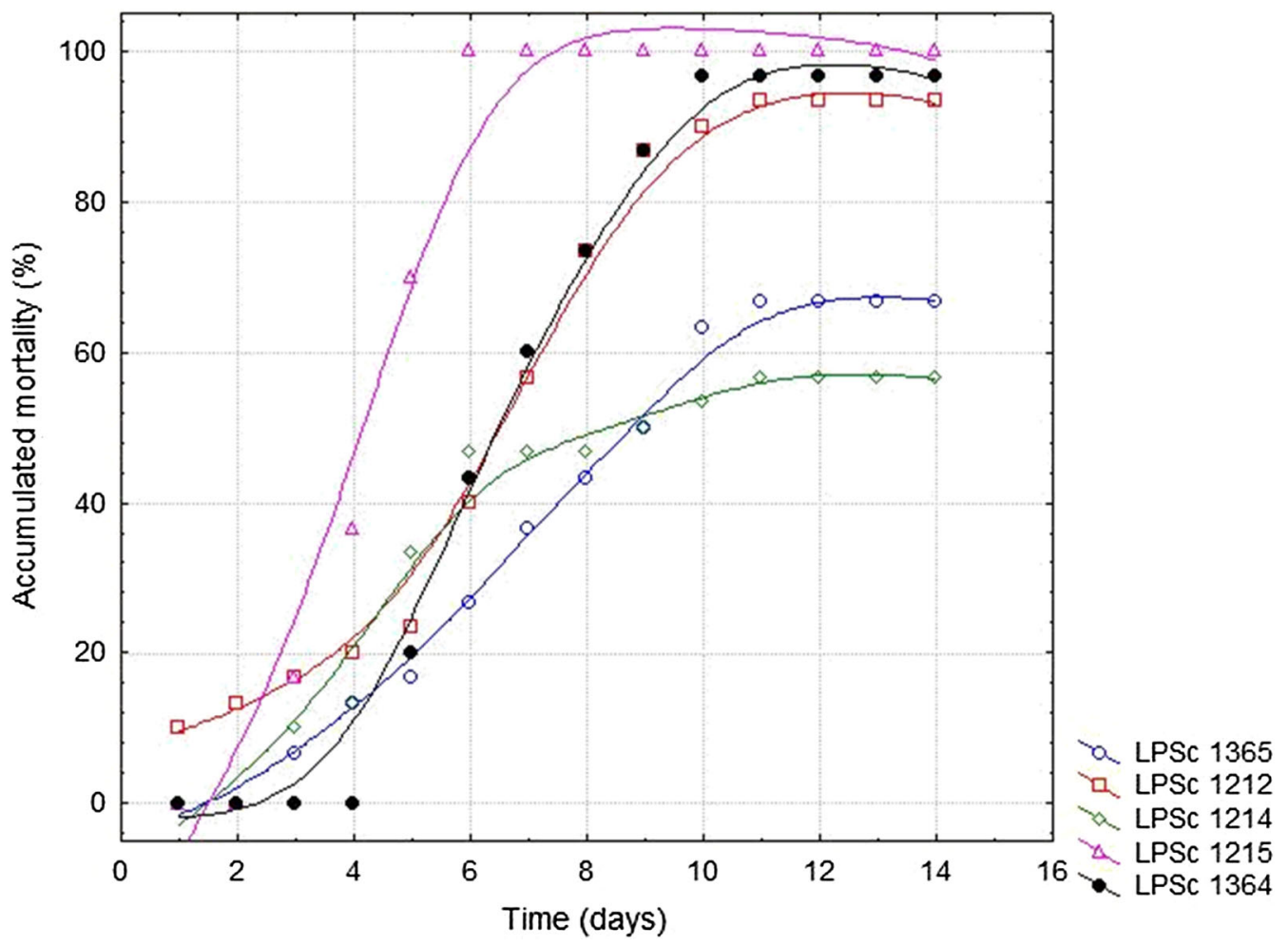

Figure 3. Accummulated mortality (\%) as a function of time (days) of Helicoverpa gelotopoeon larvae after inoculation of different strains of Beauveria bassiana and Purpureocillium lilacinum.

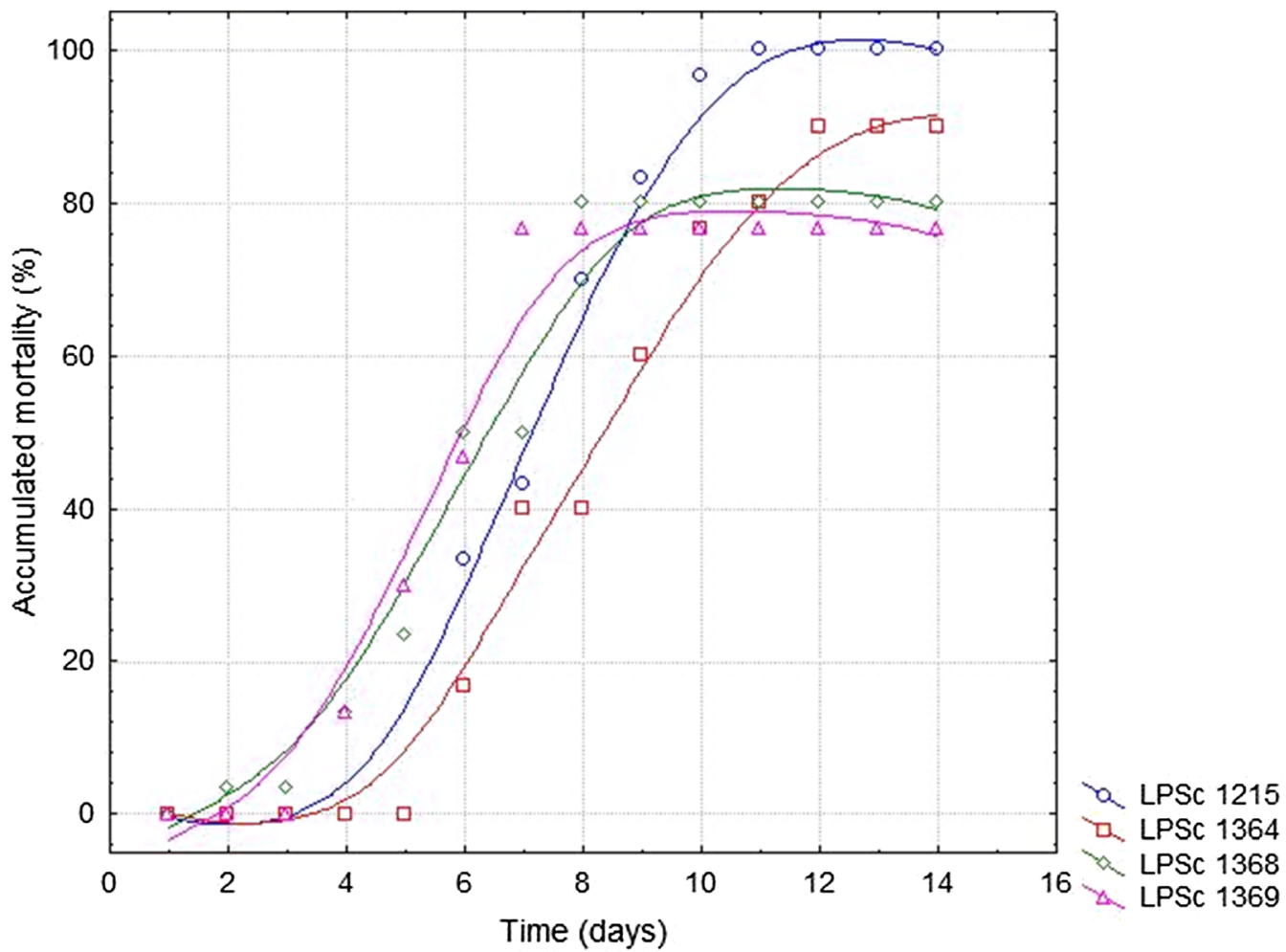

Figure 4. Accummulated mortality (\%) as a function of time (days) of Diabrotica speciosa adults after inoculation of different strains of B. bassiana and P. lilacinum. 
entomopathogenic fungi, capable to survive in tobacco soils in Jujuy province and constituting potential agents for the control of pests in this crop.

The diversity tree generated by ISSR analysis allowed to separate strains of $B$. bassiana and $P$. lilacinum, but also permitted to discriminate isolates within the same species. Studies by Takatsuka (2007), Wang et al. (2005) and Estrada et al. (2007) also demonstrated that this type of technique provides valuable information when discriminating isolates of $B$. bassiana. Furthermore, Aquino de Muro et al. (2005) who studied Beauveria species isolated from Middle East and West Asia, established that ISSR and AFLP analyses allowed correlating intraspecific groupings with genetic diversity between strains, recognizing then that this kind of methodologies are quick and reliable when describing genetic diversity of entomopathogenic fungi. In this study, three ISSR markers were used to generate banding patterns that enabled characterizing strains diversity among $B$. bassiana and P. lilacinum. Usually, the number of markers employed is higher but only a few of them are useful to discriminate between isolates (Estrada et al. 2007; Fontecha et al. 2011; Takatsuka 2007; Wang et al. 2005). According to this, the present work was based on a previous selection of three markers that were the most adequate to separate haplotypes in $B$. bassiana collected from different locations in Argentina (Toledo et al. 2019). The results indicated that markers $826, \mathrm{BA} 3$ and KA5 were also effective to detect genetic variability between isolates of $B$. bassiana and P. lilacinum collected from tobacco soils. It is interesting to mention that this study constitutes the first report for these markers to discriminate between $P$. lilacinum strains.

According to the relationship between fungal genetic diversity and pathogenicity the results show that $B$. bassiana isolates LPSc1215 and LPSc1364, recorded as the most pathogenic against both insect pests tested, were grouped in a same cluster with a similarity level of approximately $85 \%$. This cluster was located next to another cluster that included the other two isolates (LPSc1212 and LPSc1365) highly pathogenic against $H$. gelotopoeon. Respect to P. lilacinum, isolates LPSc1368 and LPSc1369, both the most pathogenic against $D$. speciosa adults, formed a single cluster with a similarity level of $98 \%$, while isolate LPSc1371, only pathogenic against $H$. gelotopoeon, was not grouped with any other isolate, but it was remained along forming a last cluster within the ISSR dendrogram. The results obtained in this work are in accordance with those recorded by Almeida Carneiro et al. (2008) who, though the use of RAPD markers, observed that $B$. bassiana and B. brongniartii (Sacc.) isolates were grouped in three different clusters according to their levels of pathogenicity against Spodoptera frugiperda (Smith) (Lepidoptera: Noctuidae). These authors detected that three RAPD polymorphic bands among Beauveria isolates were associated with the levels of pathogenicity against $S$. frugiperda and suggested a potential use of these markers as a first screening strategy of Beauveria isolates for biological control purposes against this pest. Similar results were reported by Amer et al. (2008). These authors evaluated the pathogenicity of $B$. bassiana, B. brongniartii, $M$. anisopliae, M. flavoviridae (Gams \& Roszypal) and Paecilomyces farinosus (= Isaria farinosa) (Holmsk.) Fr. against Spodoptera littoralis (Boisduval) (Lepidoptera: Noctuidae) and observed that only the highly virulent isolates $M$. anisopliae and $M$. flavoviridae showed two unique RAPD markers that were not present in the other pathogens. Their results show that RAPD markers would have diagnostic potential in identifying highly virulent isolates. Similarly, the results obtained in our investigation not only provide valuable information regarding genetic diversity of native fungal isolates and their pathogenicity against to $H$. gelotopoeon and D. speciosa, but also suggest the potential use of ISSR markers to identify isolates with different virulence against these two important pests of tobacco crops. Although future studies will be needed to establish a link among amplified bands and genes related to the ability of entomopathogenic fungi to kill insects.

\section{References}

Aljanabi SM and Martinez I 1997 Universal and rapid saltextraction of high quality genomic DNA for PCR-based techniques. Nucleic. Acids Res. 25 4692-4693

Almeida Carneiro A, Gomes EA, Teixeira Guimarães C, Tavares Fernandes F, Portilho Carneiro N and Cruz I 2008 Molecular characterization and pathogenicity of isolates of Beauveria spp. to fall armyworm. Pesqui. Agropecu. Bras. 43 513-520

Amer M., El-Sayed TI, Bakheit HK, Moustafa SA, El-Sayed YA 2008 Pathogenicity and genetic variability of five entomopathogenic fungi against Spodoptera littoralis. Res. J. Agric. Biol. Sci. 4 354-367

Aquino De Muro M, Elliott S, Moore D, Parker BL, Skinner M, William REID and El Bouhssini M 2005 Molecular characterisation of Beauveria bassiana isolates obtained from overwintering sites of Sunn Pests (Eurygaster and Aelia species). Mycol. Res. 109 294-306 
Ayala-Zermeño MA, Gallou A, Berlanga-Padilla AM, Serna-Domínguez MG, Arredondo-Bernal HC and Montesinos-Matías R 2015 Characterisation of entomopathogenic fungi used in the biological control programme of Diaphorina citri in Mexico. Biocontrol Sci. Techn. 25 1192-1207

Boetel MA, Majumdar A, Jaronski ST and Horsley RD 2012 Cover crop and conidia delivery system impacts on soil persistence of Metarhizium anisopliae (Hypocreales: Clavicipitaceae) in sugarbeet. Biocontrol Sci. Techn. 22 1284-1304

Fernández Bravo MDC 2017 Diversity, population dynamics and ecology of entomopathogenic fungi from soil and phylloplane of Mediterranean agroforestry systems and the effect of UV-B over their virulence, Doctoral Thesis, Cordoba University, Spain.

Bruck DJ 2009 Impact of fungicides on Metarhizium anisopliae in the rhizosphere, bulk soil and in vitro. BioControl 54 597-606

Cruz LP, Gaitan AL and Gongora CE 2006 Exploiting the genetic diversity of Beauveria bassiana for improving the biological control of the coffee berry borer through the use of strain mixtures. Appl. Microbiol. Biotechnol. 71 918-926

Da Silva FR, Kvitko K, Rohr P, Abreu MB, Thiesen FV and Da Silva J 2014 Genotoxic assessment in tobacco farmers at different crop times. Sci. Total Environ. 490 334-341

Dalleau-Clouet C, Gauthier N, Risterucci AM, Bon MC and Fargues J 2005 Isolation and characterization of microsatellite loci from the entomopathogenic hyphomycete, Paecilomyces fumosoroseus. Mol. Ecol. Notes. 5 496-498

de Barros NM, Fronza E and Bertholdo-Vargas LR 2015 Use of fungi as biopesticides; In: Biopesticides handbook (eds) L. M Nollet and H. S.Rathore (London, New York: CRC Press, Taylor \& Francis Group) pp 247-281

de Faria MR and Wraight SP 2007 Mycoinsecticides and mycoacaricides: a comprehensive list with worldwide coverage and international classification of formulation types. Biol. Control. 43 237-256

Domsch KH, Gams W and Anderson TH 2003 Compendium of soil fungi (New York: Academic Press) pp 894

Enkerli J, Kölliker R, Keller S and Widmer F 2005 Isolation and characterization of microsatellite markers from the entomopathogenic fungus Metarhizium anisopliae. Mol. Ecol. Notes. 5 384-386

Enkerli J and Widmer F 2010 Molecular ecology of fungal entomopathogens: molecular genetic tools and their applications in population and fate studies. BioControl. 55 17-37

Estrada ME, Camacho MV and Benito C 2007 The molecular diversity of different isolates of Beauveria bassiana (Bals.) Vuill. as assessed using intermicrosatellites (ISSRs). Cell. Mol. Biol. Lett. 12240
Fernandes EKK, Costa GL, Lage Moraes AM, Zahner V and Pinheiro Bittencourt VRE 2006 Study on morphology, pathogenicity, and genetic variability of Beauveria bassiana isolates obtained from Boophilus microplus tick. Parasitol. Res. 98 324-332

Flint SD, Miller CD, Anderson AJ and Roberts DW 2002 Damage and recovery from UV-B exposure in conidia of the entomopathogens Verticillium lecanii and Aphanocladium album. Mycologia. 94912

Fontecha G, Trabanino R, Pérez-Borrero $\mathrm{B}$, Catalán $\mathrm{P}$, Aguilar E, Gallego FJ and Benito C 2011 Molecular characterizatiom of Centro-american isolates of Beauveria bassiana for the control of the coffe drill. Revista Ciencia y Tecnología. 8 39-61

Hall TA 1999 BioEdit: a user-friendly biological sequence alignment editor and analysis program for Windows 95/98NT. Nucleic Acids Symp. Ser. 41 95-98

Hummel RL, Walgenbach JF, Barbercheck ME, Kennedy GG, Hoyt GD and Arellano C 2015 Effects of production practices on soilborne entomopathogens in western North Carolina vegetable systems. Environ. Entomol. 31 84-91

Lecuona RE 1996 Pathogenic microorganisms used in the microbial control of pest insects (Buenos Aires, Argentina: Talleres gráficos Mariano Mas) pp 338

Mercado Cárdenas G; Gimenez Monge JL and Ortega AE 2013 Manual of recognition of pests and biotic and abiotic diseases in Tobacco (Salta: INTA ediciones) $188 \mathrm{pp}$

Mishra J, Tewari S, Singh S and Arora NK 2015 Biopesticides: where we stand? In: Plant microbes symbiosis: applied facets (eds) N. K., Arora (New Delhi: Springer) pp 37-75

Nagamani A, Kunwar IK and Manoharachary C 2006 Handbook of soil fungi (New Delhi: I.K International Pvt. Ltd) pp 436

Nussenbaum AL and Lecuona RE 2012 Selection of Beauveria bassiana sensu lato and Metarhizium anisopliae sensu lato isolates as microbial control agents against the boll weevil (Anthonomus grandis) in Argentina. J. Invert. Pathol. 110 1-7

Oulevey C, Widmer F, Kölliker R and Enkerli J 2009 An optimized microsatellite marker set for detection of Metarhizium anisopliae genotype diversity on field and regional scales. Mycol. Res. 113 1016-1024

Patana R 1977 Rearing selected western cotton insects in the laboratory. U.S. Department of Agriculture, Agricultural Research Service, ARS W-51, 8

Pathan EK, Patil AV and Deshpande MV 2019 Bioprospecting of fungal entomo-and myco-pathogens. In: Advancing frontiers in mycology and mycotechnology (eds) $\mathrm{T}$ Satyanarayana, S Deshmukh and M Deshpande (Singapore: Springer) pp 497-513

Pecchioni MTD 1989 Rearing Diabrotica speciosa (Coleoptera: Chrysomelidae) under laboratory conditions. Revista Peruana de Entomología 31 86-90 
Pilz C, Wegensteiner R and Keller S 2007 Selection of entomopathogenic fungi for the control of the western corn rootworm Diabrotica virgifera virgifera. J. App. Entomol. 131 426-431

Posadas JB, Comerio RM, Mini JI, Nussenbaum AL and Lecuona RE 2012 A novel dodine-free selective medium based on the use of cetyl trimethyl ammonium bromide (CTAB) to isolate Beauveria bassiana, Metarhizium anisopliae sensu lato and Paecilomyces lilacinus from soil. Mycologia $104974-980$

Powell WA, Klingeman WE, Ownley BH, Gwinn KD, Dee M and Flanagan PC 2007 Endophytic Beauveria bassiana in tomatoes yields mycosis in tomato fruitworm larvae. HortScience 42 933-933

Rehner SA and Buckley E 2005 A Beauveria phylogeny inferred from nuclear ITS and EF1-a sequences: evidence for cryptic diversification and links to Cordyceps teleomorphs. Mycologia 97 84-98

Samson RA, Evans HC and Latgé JP 1988 Atlas of entomopathogenic fungi (Berlin: Springer-Verlag) pp 187

Sandhu SS, Shukla H, Aharwal RP, Kumar S and Shukla S 2017 Efficacy of entomopathogenic fungi as green pesticides: current and future prospects. In: Microorganisms for Green Revolution (eds) DG Panpatte, YK Jhala, $\mathrm{RV}$ Vyas and HN Shelat (Singapore: Springer) pp 327-349

Seifert K, Morgan-Jones G, Gams W and Kendrick B 2011 The genera of Hyphomycetes (Utrecht: CBS-KNAW Fungal Biodiversity Centre) pp 997

Shapiro-Ilan DI, Gardner WA, Wells L and Wood BW 2012 Cumulative impact of a clover cover crop on the persistence and efficacy of Beauveria bassiana in suppressing the pecan weevil (Coleoptera: Curculionidae). Environ. Entomol. 41 298-307

Shapiro-Ilan DI, Gardner WA, Wells L, Cottrell TE, Behle RW and Wood BW 2013 Effects of entomopathogenic fungus species, and impact of fertilizers, on biological control of Pecan weevil (Coleoptera: Curculionidae). Environ. Entomol. 42 253-261

Serna-Domínguez MG, Andrade-Michel GY, Rosas-Valdez R, Castro-Félix P, Arredondo-Bernal HC. and Gallou, A 2019 High genetic diversity of the entomopathogenic fungus Beauveria bassiana in Colima, Mexico. J. Inverteb. Pathol. 163 67-74

Sevim A, Höfte M and Demirbağ Z 2012 Genetic variability of Beauveria bassiana and Metarhizium anisopliae var. anisopliae isolates obtained from the Eastern Black Sea Region of Turkey. Turk J. Biol. 36 255-265

StatSoft Inc 2005 STATISTICA (data analysis software system), version 7.1. (www.statsoft.com)
Tamura K, Peterson D, Peterson N, Nei M and Kumar S 2011 MEGA5: molecular evolutionary genetics analysis using maximum likelihood, evolutionary distance, and maximum parsimony methods. Mol. Biol. Evol. 28 2731-2739

Takatsuka J 2007 Characterization of Beauveria bassiana isolates from Japan using inter-simple-sequence-repeatanchored polymerase chain reaction (ISSR-PCR) amplification. Appl. Entomol. Zool. 42 563-571

Taylor JW, Jacobson DJ and Fisher MC 1999 The evolution of asexual fungi: reproduction, speciation and classification. Annu. Rev. Phytopathol. 37 197-246

Thompson SR, Brandenburg RL and Arends JJ 2006 Impact of moisture and UV degradation on Beauveria bassiana (Balsamo) Vuillemin conidial viability in turfgrass. Biol. Control. 39 401-407

Tigano-Milani MS, Honeycutt RJ, Lacey LA, Assis R, Mcclellal M and Sobral BWS 1995 Genetic variability of Paecilomyces fumosoroseus isolates revealed by molecular markers. J. Inverteb. Pathol. 65 274-282

Toledo AV, Franco MEE, Medina R, Marino de Remes Lenicov AM and Balatti PA 2019 Assessment of the genetic diversity of Argentinean isolates of Beauveria bassiana (Ascomycota: Hypocreales) using ISSR markers. J. King Saud Uni. Sci. 31 1264-1270

Trissi AN, El Bouhsini M, Alsalti MN, von Korff M, Hamwieh A, Skinner M, Parker BL and Baum M 2013 Genetic diversity among summer and winter Beauveria bassiana populations as revealed by AFLP analysis. $J$. Asia-Pac. Entomol. 16 269-273

Vega FE 2008 Insect pathology and fungal endophytes. $J$. Invertebr. Pathol. 98 277-279

Wang S, Miaox X, Zhao W, Huang B, Fan M, Li Z and Huang Y 2005 Genetic diversity and population structure among strains of the entomopathogenic fungus, Beauveria bassiana, as revealed by inter-simple sequence repeats (ISSR). Mycol. Res. 109 1364-1372

White TJ, Bruns T, Lee S and Taylor J 1990 Amplification and direct sequencing of fungal ribosomal RNA genes for phylogenetics. In: PCR protocols. a guide to methods and applications (eds) MA Innis, DH Gelfand, JJ Sninsky and TJ White (San Diego: Academic Press) pp 315-322

Yang H, Qin C, Chen Y, Zhang G, Dong L and Wan S 2019 Persistence of Metarhizium (Hypocreales: Clavicipitaceae) and Beauveria bassiana (Hypocreales: Clavicipitaceae) in tobacco soils and potential as biocontrol agents of Spodoptera litura (Lepidoptera: Noctuidae). Environ. Entomol. 48 147-155

Zimmermann G 2007 Review on safety of the entomopathogenic fungi. Beauveria bassiana and Beauveria brongniartii. Biocontrol Sci. Tech. 17 553-596 